\title{
A Microstrip-Line Fed Quad-Port MIMO Antenna with Defected Ground Structures for Wireless Applications
}

\author{
Shiddanagouda F.B ${ }^{1}$, Vani.R.M ${ }^{2 *}$ and P.V.Hunagund ${ }^{3}$ \\ ${ }^{1,3}$ Department of Applied Electronics Gulbarga University Kalaburagi-585106, Karnataka India \\ ${ }^{2}$ University Science Instrumentation Center Gulbarga University Kalaburagi-585106, Karnataka India \\ siddu.kgp09@gmail.com
}

\begin{abstract}
A microstrip line fed quad-port MIMO (Multiple Input Multiple Output) antenna with defected ground structure is discussed for wireless applications. The prototype of the MIMO antenna consists of four identical rectangular microstrip antenna elements extended towards each other and printed on $1.6 \mathrm{~mm}$ thick FR-4 substrate with an overall dimension of $62.8 \times 60 \mathrm{~mm}^{2}$. The proposed MIMO antenna elements are etched out with multiple rectangular edge slits from the top of the metallic surface and ground plane defected with octagon splitring slot defected ground structure (OSRSDGS) periodically to obtain wideband operation of the antenna. The proposed MIMO antenna is resonating at the frequency $4.1 \mathrm{GHz}$ and $5.9 \mathrm{GHz}$ with a bandwidth of $98 \mathrm{MHz}$ and $475 \mathrm{MHz}$, respectively, which makes it suitable to use for wireless applications. The MIMO antenna has achieved mutual coupling less than $-33.4 \mathrm{~dB}$ in the lower band and less than $-25.6 \mathrm{~dB}$ in the upper band. The measured and simulated results show good agreement in both the bands. Moreover, the MIMO antenna parameter such as data rate, envelope correlation coefficients (ECC), and diversity gain (DG) performance have also been analyzed.
\end{abstract}

Keywords: MIMO antenna, Bandwidth, Data rate, ECC, DG.

\section{Introduction}

The growing advanced wireless communication system has drawn much attention to use MIMO system to provide high data rates due to rapid increases in wireless devices. The MIMO system is implemented with many antennas in the transmitter and receiver side and provides a better data rate without raising bandwidth and transmit power [6]. In literature, several quad port MIMO antennas have been reported and each of the reported papers uses different kinds of defected ground structures to achieve the reduction of mutual coupling between the antenna elements, as well as to obtain wideband operation of the antenna. Therefore, it becomes challenging to deploy multiple antennas in limited space and maintaining less mutual coupling in the operating frequency bands with its defected ground structure [10].

In this paper, a microstrip line fed quad-port MIMO antenna using defected ground structures for wireless applications is presented. The proposed MIMO antenna elements are etched out with multiple rectangular edge slits from the top of the metallic surface and ground plane defected with octagon split-ring slot defected ground structure (OSRSDGS) periodically to obtain wideband operation of the antenna. The performances of the antenna were examined using commercially available simulation software High Frequency Structure Simulator (HFSS). This paper is organized as follows; the 2nd section presents the design of the proposed MIMO antenna. The results and discussions are then presented in the 3rd section, followed by the conclusion in the 4th section.

\section{MIMO antenna design}

Figure 1 shows the geometry of the conventional MIMO antenna (CMA) of $62.8 \times 60 \times 1.6 \mathrm{~mm}^{3}$. The selected MIMO antenna has four identical rectangular microstrip antenna elements extended toward collinear each other with a separation of $\lambda / 4$ (where $\lambda$ is the free space wavelength) is maintained to avoid poor diversity. The antenna is designed over low-cost FR-4 substrate with loss tangent 0.02 . The detailed dimensions of the antenna are shown in Table 1 and the prototype of the CMA is shown in Figure 2, respectively.

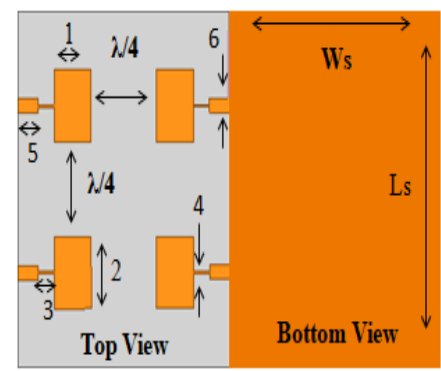

Fig. 1. Geometry of conventional MIMO antenna (CMA)

Table 1: Dimensions of CMMA

\begin{tabular}{|l|l|l|l|l|}
\hline Parameters & Ls & Ws & 1 & 2 \\
\hline Dimensions $(\mathrm{mm})$ & 60 & 62.8 & 11.35 & 15.25 \\
\hline Parameters & 3 & 4 & 5 & 6 \\
\hline Dimensions $(\mathrm{mm})$ & 4.9 & 0.5 & 6.15 & 3.06 \\
\hline
\end{tabular}

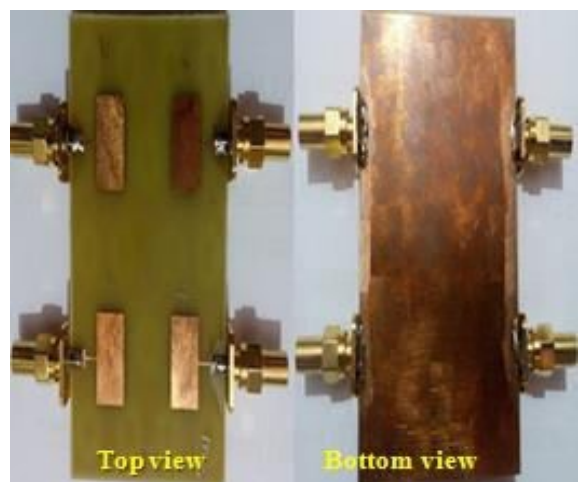

Fig. 2. Prototype of conventional MIMO antenna 
To improve the impedance matching and have a compact wideband antenna, the study carried by defected ground structure is cut on to the ground plane of CMA in the form of octagon split-ring slot defected ground structures (OSRSDGS) periodically and antenna elements are etched out with multiple rectangular edge slits from the top of metallic surface and it is named as proposed MIMO antenna (PMA). Figures 3 and 4 show the geometry and prototype of PMA. Figure 5 shows the enlarged optimized OSRSDGS geometry and final dimensions are given in Table-2.

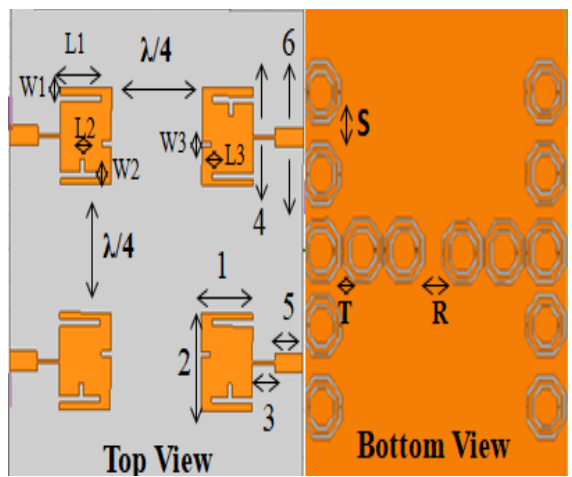

Fig. 3. Geometry of proposed MIMO antenna (PMA)

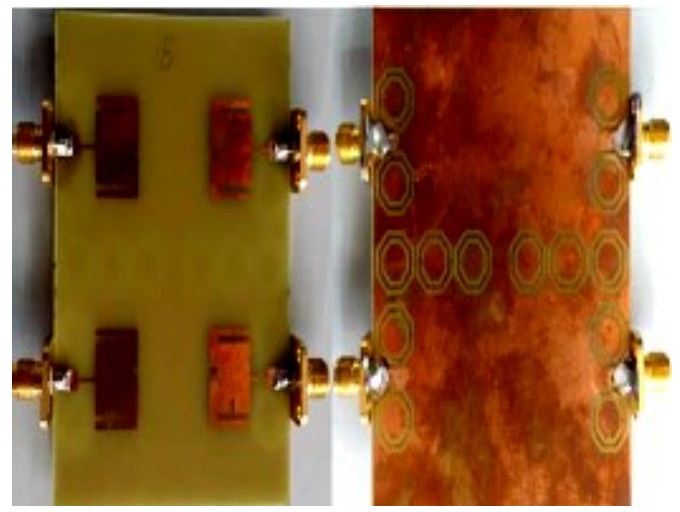

Fig. 4. Prototype of proposed MIMO antenna (PMA)

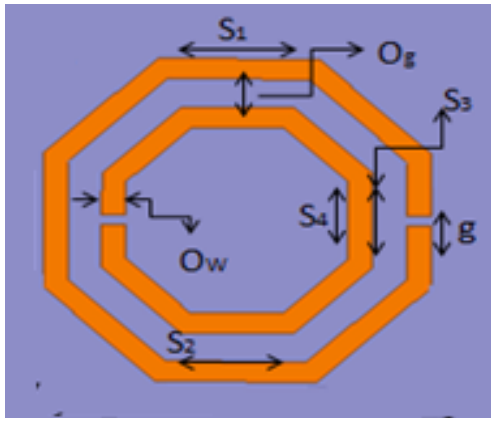

Fig. 5. Geometry of OSRSDGS

Table 2: Geometry of octagon-shaped split-ring slot defected ground structures (OSRSDGS)

\begin{tabular}{|l|l|}
\hline Parameters & Dimensions (mm) \\
\hline $\mathrm{S} 1, \mathrm{~S} 2, \mathrm{~S} 3, \mathrm{~S} 4$ & $4,3.5,2.8,2.3$ \\
\hline $\mathrm{Og}$ & 0.845 \\
\hline $\mathrm{g}$ & 0.3 \\
\hline $\mathrm{O}_{\mathrm{W}}$ & 0.6 \\
\hline
\end{tabular}

The distributions of periodic defected ground structures in the ground plane have drawn much attention for their extensive applications in antenna design [10]. Periodic means repetition of defected ground structure unit cells with finite space. The corresponding OSRSDGS unit cells are aligned with equal spacing of ' $S$ ' $=10 \mathrm{~mm}$, vertically to both radiating edges and four OSRSDGS unit cells are placed horizontal direction with a space of ' $\mathrm{T}$ ' $=7 \mathrm{~mm}$ between vertical OSRSDGS and the center gap between the horizontal OSRSDGS maintained with a space of ' $R$ ' $=12 \mathrm{~mm}$. The complete ground plane looks like an " $H$ " shape periodic structure. Then antenna elements are etched out with optimized multiple rectangular edge slits from the top of metallic surface are $(\mathrm{L} 1, \mathrm{~W} 1)=(10 \mathrm{~mm}, 0.5 \mathrm{~mm}),(\mathrm{L} 2$, $\mathrm{W} 2)=(0.5 \mathrm{~mm}, 2 \mathrm{~mm})$ and $(\mathrm{L} 3, \mathrm{~W} 3)=(2 \mathrm{~mm}, 0.5 \mathrm{~mm})$ as shown in Figures 3 and 4, respectively. These DGS structures and edge slits are used to suppress unwanted surface waves and to control harmonics in microstrip antennas to enhance the performance in terms of dual-band resonances, bandwidth enhancement, and to size reduction as well as mutual coupling reduction, thus improving the antenna efficiency. The proposed antenna resonates dualband frequency points along with wide bandwidth and low mutual coupling between the antenna elements as compared to CMA and other proposed MIMO antennas available so for in the literature.

\section{Results and discussions}

The $S$-parameters of the antenna is tested using a Vector network analyzer (VNA) (Rhode and Schwarz, Germany make ZVK model 1127.8651). Figure 6 shows the comparison of simulated and measured reflection characteristics of the conventional MIMO antenna (CMA). It can be observed that CMA resonates at $5.9 \mathrm{GHz}$. The return loss obtained at the resonating frequency is equal to $21.3 \mathrm{~dB}$ and bandwidth equal to $204 \mathrm{MHz}$.

The key feature of MIMO systems is their potential ability to turn multipath propagation, for sending the information through ' $n$ ' different channel connecting $n$ different transmitter and receivers. Thus the MIMO capacity would become

$$
C=\operatorname{Blog}_{2}\left(\operatorname{det}\left(\mathrm{IM}_{\mathrm{M}}+\frac{\mathrm{S}}{\mathrm{N}} \mathrm{HH}^{*}\right)\right)
$$

Where $\mathrm{I}_{\mathrm{M}}$ is an identity matrix and $\mathrm{HH}^{*}$ is a channel matrix, both matrix size depends on the number of a patch antenna on both Rx/Tx side of the MIMO system

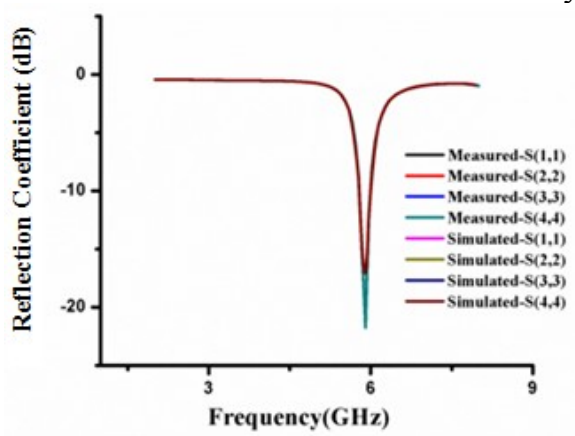

Fig. 6.: Reflection characteristics of CMA 


$$
\mathrm{IM}=\left[\begin{array}{lll}
1 & \mathrm{~L} & 0 \\
\mathrm{M} & \mathrm{O} & \mathrm{M} \\
0 & \mathrm{~L} & 1
\end{array}\right] \quad \mathrm{H}=\left[\begin{array}{ccc}
\mathrm{H}_{1,1} & \mathrm{~L} & \mathrm{H}_{1, \mathrm{~T}} \\
\mathrm{M} & \mathrm{O} & \mathrm{M} \\
\mathrm{HR}_{\mathrm{R}, 1} & \mathrm{~L} & \mathrm{HR}_{\mathrm{R}, \mathrm{T}}
\end{array}\right]
$$

This is the new channel capacity of the MIMO system is inherently higher than the Shannon theorem. To calculate the channel capacity of the MIMO system, we assumed the given signal to noise ratio (SNR) is $32 \mathrm{~dB}$ [8]. So from the calculation, it is observed that CMA bandwidth supports a data rate of $10 \mathrm{Gbps}$.

Figure 7 shows the comparison of simulated and measured return loss characteristics of the proposed MIMO antenna (PMA). It can be observed that PMA resonates at dual resonating frequency points i.e., $4.1 \mathrm{GHz}$ and $5.9 \mathrm{GHz}$, with a bandwidth of $98 \mathrm{MHz}$ and $475 \mathrm{MHz}$ along with minimum return loss of $-12.07 \mathrm{~dB}$ and $-16.87 \mathrm{~dB}$ respectively. So from equation (1) and (2) is observed that PMA bandwidth supports a data rate of $4.80 \mathrm{Gbps}$ and $23.35 \mathrm{Gbps}$, respectively.

The above result shows that due to the multiple rectangular edge slits from the top of the metallic surface as well as the periodic distribution of OSRSDGS unit cells in the ground plane gives the virtual size reduction of $30.5 \%$ using equation (3). Where $\mathrm{L}_{\mathrm{RA}}$ is the patch length of the reference antenna $(\mathrm{CMA}), \mathrm{L}_{\mathrm{C}}$ is the patch length of the antenna resonating at a lower frequency or at reduced resonant frequencies (PMA). But the width of the patch is same at both designed (CMA) and actual resonating frequencies (PMA).

$$
\text { Virtual Size reduction }(\%)=\left(\frac{L_{C}-L_{R A}}{L_{C}}\right) \times 100
$$

Figure 8 shows the comparison of simulated and measured mutual coupling coefficients of the conventional MIMO antenna (CMA). This antenna gives mutual coupling between port1 and port 2 is $-20.9 \mathrm{~dB}$ at $5.9 \mathrm{GHz}$. From the figure, we can conclude that the mutual coupling affects the radiation performance of the CMA due to the common ground plane. In order to improve the coupling effect with the use of a defected ground structure is cut on to the ground plane in the form of OSRSDGS periodically. It helps in reducing the flow of current from one element to another

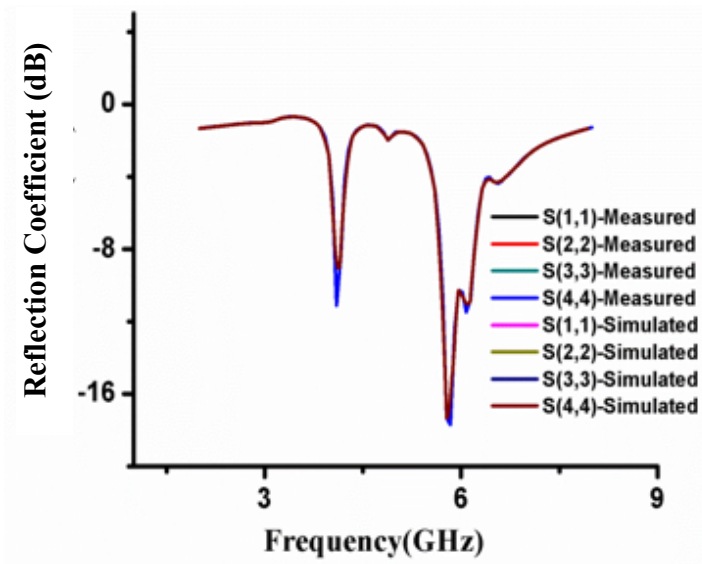

Fig. 7. Reflection characteristics of PMA

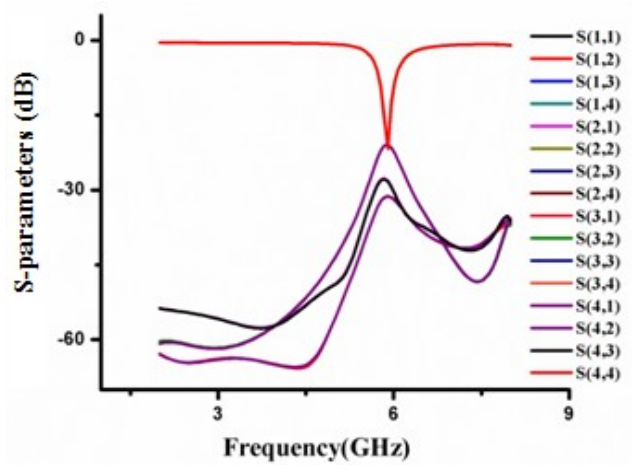

Fig. 8. Mutual Coupling Coefficient of CMA

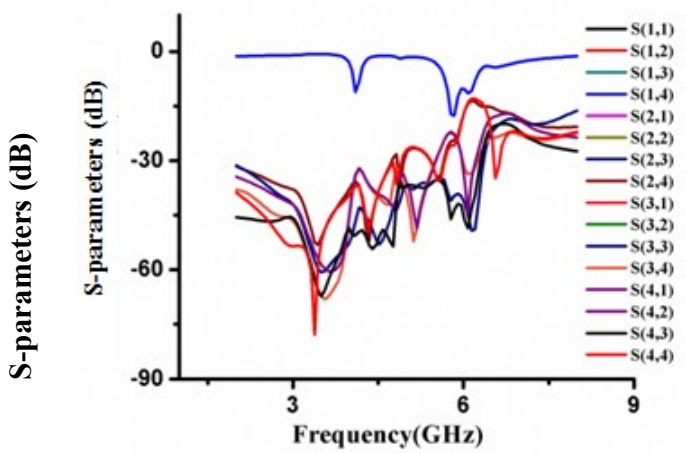

Fig. 9. Mutual Coupling Coefficient of PMA

element. It clearly shows the ground plane coupling has been interrupted increasing the isolation at both the band i.e., $33.4 \mathrm{~dB}$, at $4.1 \mathrm{GHz}$ and $-25.6 \mathrm{~dB}$ at $5.9 \mathrm{GHz}$ are verified with $S$-parameter response of the proposed MIMO antenna (PMA) in Figure 9.

The Envelope Correlation Coefficient (ECC) determines how much the communication channels are isolated and the lower value of ECC signifies higher pattern diversity [9]. The envelope correlation coefficient (ECC) between the antenna elements is calculated from the equation (4).

$$
\rho=\frac{\left|S_{11}^{*} S_{12}+S_{21}^{*} S_{22}\right|^{2}}{\left(1-\left|S_{11}\right|^{2}-\left|S_{21}\right|^{2}\right)\left(1-\left|S_{22}\right|^{2}-\left|S_{12}\right|^{2}\right)}
$$

ECC performance between elements of the conventional MIMO antenna (CMA) is 0.001 for the operating band which is shown in Figure 10. Diversity Gain (DG) of the MIMO antenna is calculated by using equation (5) which is correlated to ECC. DG performance of the CMA is found to be $9.9 \mathrm{~dB}$ for the operating band.

$$
\mathrm{DG}=10 \sqrt{\left(1-|\rho|^{2}\right)}
$$

ECC performance of the proposed MIMO antenna (PMA) is found well below 0.00001 for both operating bands, which is shown in Figure 11. DG performance of the PMA is found to be $10 \mathrm{~dB}$ for both operating bands. Hence the overall performance of the proposed MIMO antenna is improved. The proposed MIMO antenna is compared with conventional MIMO antenna regarding return loss characteristics, the number of bands, covering bandwidth, size reduction, data rate, mutual coupling coefficients, ECC and DG are summarized in Table 3. 


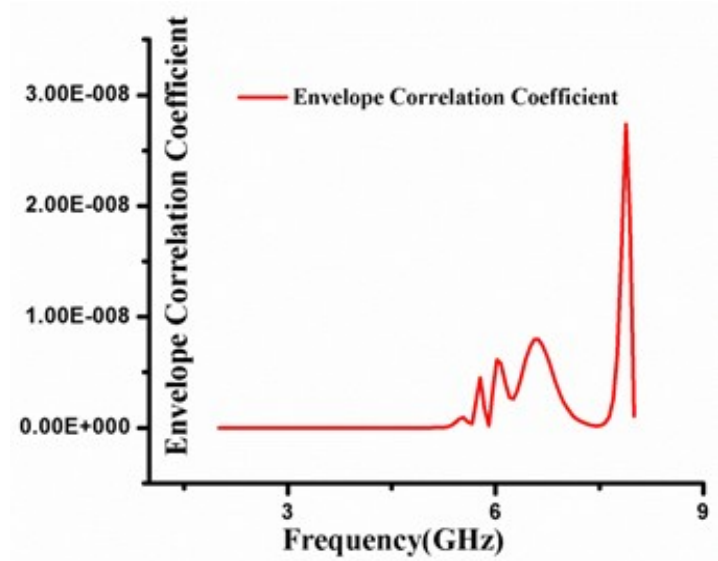

Fig. 10. Envelope Correlation Coefficient of CMA

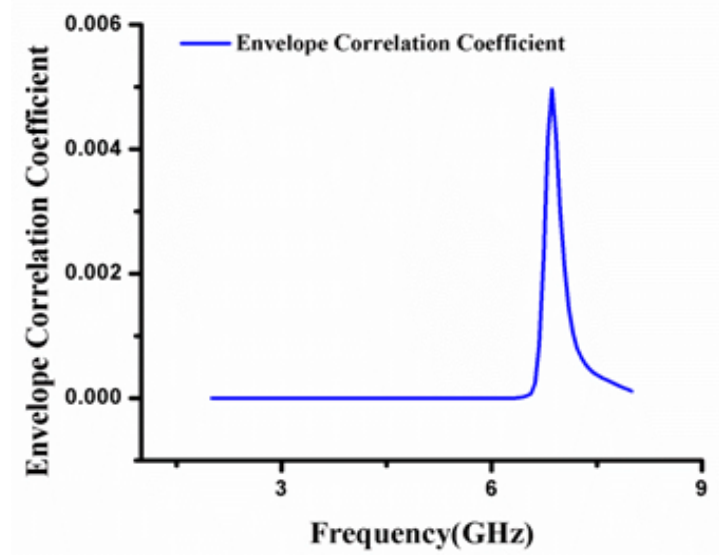

Fig. 11. Envelope Correlation Coefficient of PMA

Table 3: Summarized results of the CMA and PMA

\begin{tabular}{|l|l|l|l|}
\hline Parameters & CMMA & \multicolumn{2}{|l|}{ PMMA } \\
\hline $\begin{array}{l}\text { Resonating Frequency } \\
(\mathrm{GHz})\end{array}$ & 5.9 & 4.1 & 5.9 \\
\hline Return Loss (dB) & 21.3 & 12.07 & 16.87 \\
\hline Bandwidth (MHz) & 204 & 98 & 475 \\
\hline MCC (dB) & 20.9 & 33.4 & 25.6 \\
\hline Data Rate (Gbps) & 10 & 4.80 & 23.35 \\
\hline ECC & 0.001 & 0.00001 & 0.00001 \\
\hline Diversity Gain(dB) & 9.9 & 10 & \\
\hline Virtual Size Reduction (\%) & - & 30.5 & \\
\hline
\end{tabular}

\section{Conclusion}

This paper presents a microstrip line-fed quad-port MIMO antenna using defected ground structures. The proposed MIMO antenna covers $4.1 \mathrm{GHz}$ and $5.9 \mathrm{GHz}$ operating bands for wireless applications. Due to the multiple rectangular edge slits from the top of the metallic surface and ground plane defected with octagon split-ring slot defected ground structures (OSRSDGS) in a periodical manner, mutual coupling between the elements better than $-33.4 \mathrm{~dB}$ and $25.6 \mathrm{~dB}$ isolation in $4.1 \mathrm{GHz}$ and $5.9 \mathrm{GHz}$ band respectively. The proposed design presents wide bandwidth, high data rate and low envelope correlation coefficient with compact size, which makes it suitable to use for wireless applications.

\section{Acknowledgment}

The authors are thankful to the Indian Institute of Technology Kharagpur to provided licensed versions of HFSS simulation software and the Department of Science and Technology (DST) Government of India, New Delhi, provided antenna measurement research facility to Department of Applied Electronics Gulbarga University Kalaburgi under FIST project. Further, we would like to thank for the process of photo etching and the PCB fabrication process is done from Atlantic Engineering Enterprise ECIL, Hyderabad.

\section{References}

[1] S. Fizzah and M. Abid, Design and analysis of UWB MIMO with enhanced isolation, Proceedings of International Electrical Engineering Conference, 2018.

[2] M. S. Han and J. H. Choi, Compact multi-band MIMO antenna for next-generation USB dongle applications, IEEE Antennas and Propagation Society International Symposium, vol, 2, pp. , 11-17 July 2010.

[3] X. Cheng and B. yu, L. Yang, J. .Zhang, G. Liu, Y. Wu, and L.Wan Communication in the real world 3D MIMO, IEEE Wireless Communications, vol.14, pp.136-144, 2014.

[4] Y. -J. Chi and Fu-Chirang, 4-Port quadric-polarization diversity antenna with novel feeding network, Proceedings of the Asia Pacific Microwave Conference, 2012.

[5] D..M. Pozar, Microstrip Antennas and Arrays on chiral substrates, IEEE Transactions on Antenna and Propagation, vol. 40, pp. 1260-1263, 1992.

[6] R. Zahn and P. Shutie, Advanced antenna technologies for Xband SAR, International Geoscience and Remote Sensing Symposium, IGARSS '95. Quantitative Remote Sensing for Science and Applications, 10-14 July, 1995.

[7] D.i wu and S. Cheung, Design of a printed multiband MIMO antenna, $7^{\text {th }}$ European Conference on Antenna and Propagation, 2013..

[8] Muhammad U and Ashley Steffes, A 4-element MIMO antenna system loaded with CSRRs and patch antenna elements, $7^{\text {th }}$ European Conference on Antenna and Propagation, 2013

[9] A. Alhegazi and N.Azawan, Compact UWB filtering antenna with controllable WLAN band rejection using defected microstrip structure, International Journal of Electromagnetic Radio Engineering, vol. 27, pp. 110-117, 2018

[10] M. K. Mandal and S. Sanyal, A Novel Defected Ground Structure for planar circuits, IEEE Microwave and Wireless Components Letters, vol. 16, pp. 93-95, February 2006.

[11] K. Goswami, A. Dubey, G. C. Tripathi, and B. Singh, Design and analysis of rectangular microstrip antenna with $\mathrm{PBG}$ structure for enhancement of bandwidth, International Journal of Computational Intelligence Techniques, vol. 11, pp. 112113, 2011.

[12] M. Kumar and Vandana Nath, Analysis of low mutual coupling compact multi-band compact antenna and its array using defected ground structure, Engineering science and Technology, an International Journal, vol. 19, pp. 86666-874, 2016.

[13] J. C. Rao and N.V. Rao, Compact UWB MIMO slot antenna with defected ground structure, ARPN Journal of Engineering and Applied Sciences, vol.11, pp. 10487-10495, 2016.

[14] R. Patel and A. Desai, An electrically small antenna using defected ground structure for RFID, GPS, and IEEE 802.11 $\mathrm{a} / \mathrm{b} / \mathrm{g} / \mathrm{s}$ applications, Journal of Progress in Electromagnetic Research Letters, vol. 75, pp. 75-81, 2018.

[15] T. Agrawal and S. Shrivastava, Compact MIMO antenna for multiband mobile applications, Journal of Microwaves Optoelectronics and Electromagnetic Applications, vol. 16, 2016.

[16] F.B. Shiddanagouda, R. M. Vani, Design and analysis of printed MIMO antenna for next generation Wireless 
Applications, IEEE Indian Conference on Antennas and Propagation (InCAP) 2018

\section{Biography of the authors}

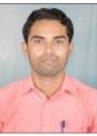

Shiddanagouda. F.B received his M.Tech and Ph.D. from IIT Kharagpur and Gulbarga University Kalaburagi in the year 2012 and 2019 respectively. He has published more than 10 papers in national and international journals. His active area of research and teaching interests are in the domain of computational electromagnetic and RF \& Microwave antennas.

Vani. R. M received her BE and M.Tech from BIET Davangere and S.J.C.E Mysore, Karnataka. She has received her Ph.D. in Applied Electronics Gulbarga University Kalaburagi, India in the year 2005. She is working as Head, University Science
Instrumentation Centre, Gulbarga University Kalaburagi. She has more than 85 research publications in national and international reputed journals. She presented the research paper in the national and international conferences in India and abroad. Her areas of interest are microwave antennas, FSS and defected ground structures.

P. V. Hunagund received his M.Sc. and Ph.D. from Department of Applied Electronics Gulbarga University Kalaburagi India, in the year 1982, and 1992 respectively. $\mathrm{He}$ is working as a Professor and chairman of the Applied Electronics Department Gulbarga University Kalaburagi. He has published more than 100 research papers in national and international reputed journals. He has presented more than 30 research paperss in the national and international conferences in India and abroad. His areas of interests is microwave antennas and wireless communication systems. 